\title{
Role of Imaging in Left Atrial Appendage Occlusion
}

\author{
Mathieu Lempereur ${ }^{1,}$, Adel Aminian ${ }^{2}$, Raluca Dulgheru ${ }^{1}$, Tom \\ De Potter ${ }^{3}$, Cécile Oury ${ }^{1}$, Patrizio Lancellotti ${ }^{1,4, *}$
}

${ }^{1} \mathrm{MD}$, University Hospital of Liège, GIGA Cardiovascular Sciences, Imaging Cardiology Liège, Liège, Belgium

${ }^{2} \mathrm{MD}$, Centre Hospitalier Universitaire de Charleroi, Charleroi, Belgium

${ }^{3} \mathrm{MD}$, Arrhythmia Unit, Cardiovascular Center, OLV Hospital, Aalst, Belgium

${ }^{4} \mathrm{MD}$, Gruppo Villa Maria Care and Research, Anthea Hospital, Bari, Italy

* Corresponding author: Patrizio Lancellotti and Mathieu Lempereur, Department of Cardiology, University Hospital Sart Tilman, B - 4000 Liège, Belgium. Tel: + 32.4.366.71.94, Fax: + 32.4.366.71.95.E-mail: plancellotti@chu.ulg.ac.be and

DOI: $10.21859 /$ ijcp-020203 mathieu.lempereur@chu.ulg.ac.be

Submited: 02.23.2017

Accepted: 03.05.2017

Keywords:

Left atrial Appendage

Occlusion

Echocardiography

2D/3D Echocardiography

Echocardiography, Doppler

Cardiac computed

Tomography Angiography

\begin{abstract}
Percutaneous left atrial appendage (LAA) occlusion is now a valid alternative to longterm oral anticoagulation in patients with non-valvular atrial fibrillation at high thromboembolism risk, especially for patients who are considered ineligible for anticoagulation. The most frequently used occluders worldwide include the WATCHAMN (Boston Scientific, Natick, MA, USA) and the Amplatzer Cardiac Plug or Amulet (St. Jude Medical/Abbott, St Paul, MN, USA) devices. Multimodality imaging is key in the understanding of $3 \mathrm{D}$ aspects of the LAA and surrounding structures anatomy. Imaging is essential for procedural planning, during each step of the procedure and for device surveillance after implantation. Multimodality imaging, including 2D/3D echocardiography, fluoroscopy, and cardiac computed tomography can increase the safety and efficacy of the procedure.
\end{abstract}

(C) 2017. International Journal of

Cardiovascular Practice.

\section{INTRODUCTION}

Left atrial appendage (LAA) occlusion is increasingly recognized as a valid non-pharmacologic therapy for stroke prevention in high-risk patients with non-valvular atrial fibrillation (AF), especially in cases where long-term oral anticoagulation (OAC) therapy is contraindicated. Two randomized-controlled trials, the PROTECT AF and PREVAIL studies, have shown the safety and efficacy of this procedure in patients randomized to either LAA closure with the WATCHMAN device (Boston Scientific, Natick, MA, USA) or warfarin therapy $[1,2]$. Two large registries in patients who were mostly contra-indicated or deemed unsuitable to long-term anticoagulation and treated with the Amplatzer Cardiac Plug (ACP) (St. Jude Medical/Abbott, St Paul, MN, USA) (ACP multicenter registry) [3] or the WATCHMAN (Ewolution registry) [4] have confirmed safety and efficacy of this procedure in this population. Currently, the European Society of Cardiology (ESC) guidelines for the management of AF recommend that LAA closure may be considered in patients with high-risk of stroke and contraindications to long-term OAC (class IIb, level of evidence B) [5]. The 2014 American (ACC/AHA/HRS) guidelines on management of AF have not made any recom- mendation on this procedure [6]. Food Drug Administration approval in the USA for the WATCHMAN device was obtained in March 2015 for patients with non-valvular AF and high-risk of stroke who have an appropriate rationale to seek a non-pharmacologic alternative to warfarin.

Imaging is a key part of LAA occlusion as it portends patient selection, device selection, procedural guidance and post-implantation surveillance. Different imaging modalities are currently used for each of these steps, as multimodality imaging in this procedure has the potential to improve procedure safety and efficacy. Close collaboration and excellent communication between the operator and the imaging specialist are essential. The implanting team has to understand the various steps of the procedure, its complexity and $3 \mathrm{D}$ anatomy of the LAA and surrounding structures. This review will focus on the role of imaging in LAA closure with the most commonly used devices, the WATCHMAN and the ACP/Amulet. After explaining the role of imaging in the different steps of the procedure, specific aspects will be developed with emphasis on transoesophageal echocardiography (TOE) and cardiac computed tomography angiography (CCTA). 
Characteristics of the ACP/Amulet and Watchman Devices

The ACP or Amulet (second generation ACP) devices are self-expanding nitinol devices made of a distal lobe, designed to anchor the device in the LAA, connected by a short mobile waist to a proximal disc, covered by polyester patches and intended to seal the LAA orifice [7]. ACP sizing depends on the widest landing zone. It is recommended to oversize the device by $2-4 \mathrm{~mm}$ for the ACP and 3-6 $\mathrm{mm}$ for the Amulet from the widest measured landing zone. The WATCHMAN device is a self-expanding nitinol frame structure with fixation barbs and a permeable polyester fabric cover [8]. WATCHMAN sizing is based on the maximum LAA diameter, which should be 17 to $31 \mathrm{~mm}$ to accommodate available devices. A 8-20\% compression ratio based on the widest measurement is recommended by the manufacturer, while most implanters will aim for the higher compression range (close to 20\%). Given that the WATCHMAN is almost as long as it is wide, the depth of the distal (implant) lobe has to be as deep as the diameter of the device chosen.
ROLE OF IMAGING IN PROCEDURAL STEPS

\section{Pre-Procedural Planning}

Baseline assessment of the LAA days to weeks prior to the procedure is a recommended standard of practice for percutaneous LAA occlusion. This evaluation will gather information about presence of thrombus, LAA morphology and size, other cardiac structures and will exclude contra-indications for LAA closure. TOE is the preferred modality but alternative (in case of contraindications to TOE) or complementary imaging by CCTA is increasingly performed $[9,10]$. Many authors judge the presence of thrombus as an absolute contra-indication for LAA closure. If thrombus is detected during the pre-procedural work-up, anticoagulation should be initiated or intensified for at least 3-4 weeks with repeated imaging to confirm thrombus resolution before proceeding with LAA occlusion [6]. LAA morphology and dimensions can be identified in the pre-procedural study. The orifice diameter, the landing zone diameter and the depth of the LAA can be measured. This will orient device selection and ensure that LAA closure is feasible.

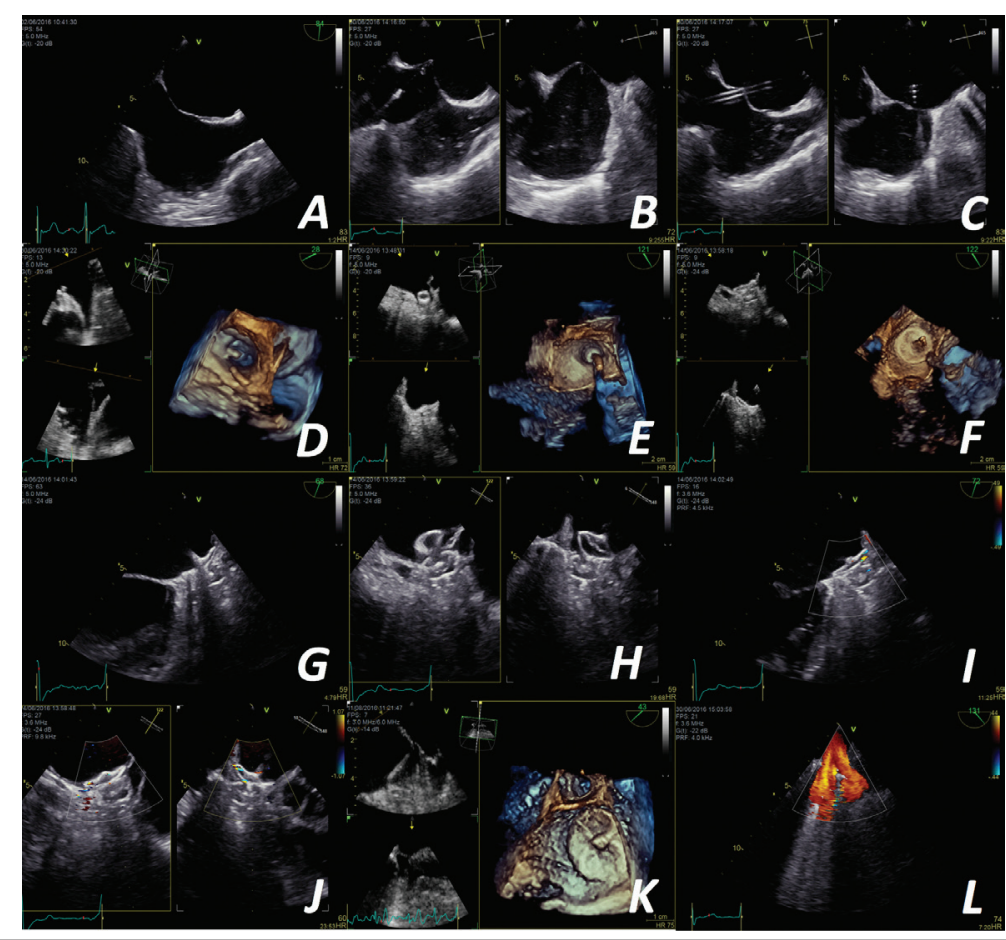

Figure 1: Step-by-step 2D/3D Transoesophageal (TOE) Guidance for Left atrial Appendage (LAA) Occlusion with an Amulet Device.

A: Step 1: The transseptal needle is pulled down with imaging guidance in the bicaval view (from superior to inferior positioning).

B: Step 2: Bicaval and short-axis views allowing visualization of the needle tenting on the fossa ovalis. The goal is to puncture in the infero-posterior region of the fosa ovalis. The use of X-plane or Bi-plane view is recommended.

C: Step 3: Gentle advancement of the guide through the interatrial septum (IAS) is tracked in X-plane or Bi-plane view.

D: Step 4: The pigtail catheter is advanced inside the LAA. Real-time 3D TOE with zoom is the preferred modality for guidance.

E: Step 5: Positioning and deployment of the device lobe inside the LAA is followed on 3D TOE.

F: Step 6: Real-time 3D TOE with zoom shows the deployment of the disc at the level of the LAA orifice. The saddling of the disc in the LAA orifice can be imaged with 3D zoom mode.

G: Step 7: Position of the device lobe inside the LAA in relationship with the left circumflex (LCx) artery is assessed. 60 to $90^{\circ}$ views on $2 \mathrm{D}$ will image the LCx artery.

H: Step 8: A tug test is performed to test device stability inside the LAA.

I and J: Step 9: Once the final position is considered appropriate, residual peri-device leaks are looked for with $2 \mathrm{D}$ color flow mode with adapted velocities at $45^{\circ}$, $60^{\circ}, 90^{\circ}$ and $135^{\circ}$. Bi-plane views with color-flow can also be used (panel J).

K: Step 10: On 3D zoom, the anatomic relationship between the disc of the device, the left pulmonary veins and the mitral valve are evaluated.

L: Step 12: Color flow Doppler of the left pulmonary veins is performed together with pulsed-wave Doppler to exclude any compression on the pulmonary veins by the device. 
The orientation of the LAA may help operators in selecting the type of access sheath. Characteristics of the inter-atrial septum (IAS) will be assessed as some features may be associated with a difficult transseptal puncture (TSP). For instance, the presence of thick or aneurysmal IAS will be evaluated.

\section{Procedural Guidance}

Interventions are performed with fluoroscopy while TOE allows guidance during the different procedural steps (Fi 1). TOE guidance during TSP is an important step as a puncture in the optimal infero-posterior region of the fossa ovalis may greatly facilitate further steps of LAA occlusion. Live TOE guidance improves safety of the TSP and increases the likelihood of an optimal TSP location. Wire and pigtail catheter position can also be identified more easily with TOE and procedure time may be shortened with guidance. Sheath positioning is visualized with TOE and fluoroscopy, ensuring a good co-axial alignment and access to the culprit (or implant) lobe. LAA morphology and sizing will be estimated by both imaging in several incidences. It is important to ensure that adequate filling pressure is present within the LA cavity to avoid underestimation of the dimension of the LAA landing zone [11]. Successful implantation is evaluated based on pre-specified criteria; different for each device and ensuring complete seal and good stability. The presence of complications is best assessed by TOE (e.g., pericardial effusion, mitral valve impingement, left pulmonary vein occlusion).

\section{Post-Procedural Device Surveillance}

We routinely perform Chest X-ray and transthoracic echocardiography (TTE) before patient discharge to ensure the absence of device embolization and pericardial effusion. Post-procedural TOE and/or CCTA can be performed 1-3 months post-implantation. Imaging will assess presence of device-associated thrombus (DAT) and peri-device leaks and will rule out any complication (e.g., device embolization, pericardial effusion). Results of post-implantation imaging are used in many centers to modify antithrombotic treatment (switch form warfarin to dual antiplatelet therapy (DAPT) or from DAPT to aspirin alone). Further imaging is indicated in case of clinical events potentially related to device complication (Table 1).

\section{ROLE OF IMAGING IN SPECIFIC SITUATIONS OR INDICATIONS}

\section{Sizing}

Correct sizing is of utmost importance for the optimization of the efficacy and safety of the procedure. Proper sizing will allow complete closure of the LAA with good device stability. Undersizing may increase peri-device leakage and increases the risk of device instability leading to dislodgement and embolization. Oversizing increases the risk of pericardial effusion, cardiac perforation and cardiac tamponade, long-term erosion and device instability. Thus, precise knowledge of LAA orifice dimensions is crucial for the selection of the occluder size. The measurements should be performed when the LAA size is the largest, at the end of the ventricular systole and under normal LA filling conditions. Performing multiple measurements in different views and ideally with multiple imaging modalities is necessary in order to select the proper device type and appropriate device size for LAA closure. Depending on the device used, specific measurements will be performed. The short-axis view enables measurements of maximal LAA diameters while the long-axis view allows measurement of the LAA depth. With the probe in mid-oesophageal position, TOE imaging planes from $0-135^{\circ}$ are obtained to perform measurements. 3D TOE may also be useful to find maximal and mean diameters. On CCTA, 3D multiplanar reconstruction (MPR) is typically used. Given the orientation of LAA, standard orthogonal views are indeed inadequate. $2 \mathrm{D}$ oblique measurements are used after manipulation of cross-sectional orthogonal views. After identification of the LAA orifice in a plane showing the circumflex artery and the pulmonary vein ridge, an orthogonal plane is obtained to ensure good co-axial alignment. The orthogonal "end-on" view allows measurements of LAA dimensions at selected area of interest (Fi 2).

\begin{tabular}{|c|c|c|c|c|}
\hline Evaluation & Fluoroscopy & TOE & ICE & CCTA \\
\hline \multicolumn{5}{|l|}{ Pre-procedural planning } \\
\hline Absence of thrombus in the LAA & NA & ++ & NA & ++ \\
\hline LAA morphology, orientation and size (length and diameters) & NA & ++ & NA & ++ \\
\hline Inter-atrial septum assessment & NA & ++ & NA & + \\
\hline \multicolumn{5}{|l|}{ Per-procedural guidance } \\
\hline Absence of thrombus in the LAA & - & ++ & ++ & NA \\
\hline Transseptal puncture & + & ++ & ++ & NA \\
\hline Wires, catheters and sheath positioning & ++ & ++ & + & NA \\
\hline Implantation success & + & ++ & ++ & NA \\
\hline Peri-device leak & - & ++ & ++ & NA \\
\hline Pericardial effusion & - & ++ & ++ & NA \\
\hline Interaction of the device with other cardiac structures & - & ++ & ++ & NA \\
\hline Embolization & ++ & + & + & NA \\
\hline \multicolumn{5}{|l|}{ Post-procedural device surveillance } \\
\hline Implantation success & NA & ++ & NA & ++ \\
\hline Peri-device leaks & NA & ++ & NA & ++ \\
\hline Device-associated thrombosis & NA & ++ & NA & ++ \\
\hline Embolization & NA & + & NA & ++ \\
\hline Pericardial effusion & NA & ++ & NA & + \\
\hline
\end{tabular}

++: very useful; +: useful; -: inappropriate; NA: not applicable

Abbreviations: LAA: left atrial appendage; ICE: intracardiac echocardiography; TOE: transoesophageal echocardiography High quality figures are available as online supplements. 


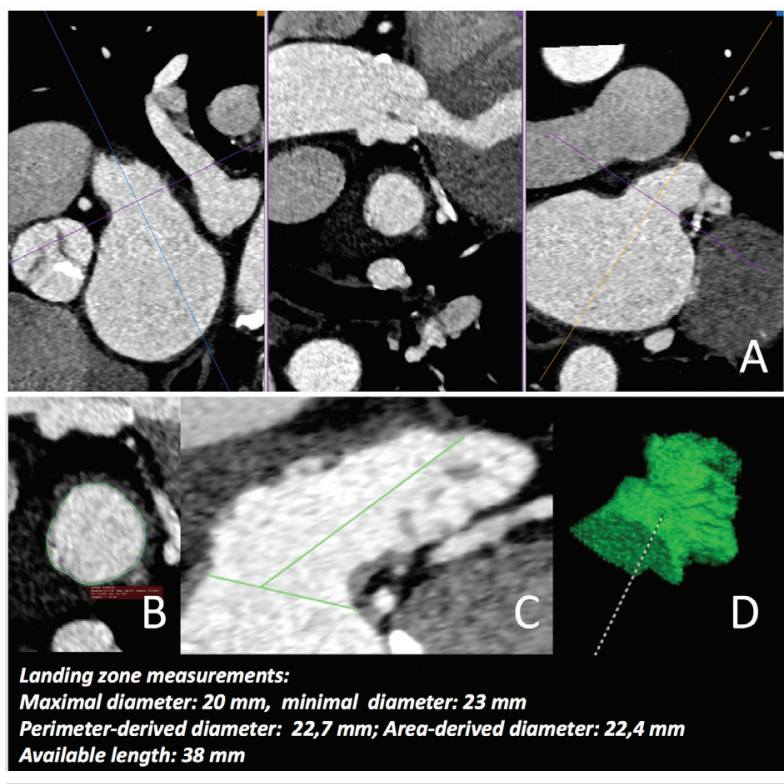

Figure 2: Cardiac Computed Tomography Evaluation of a Patient Before Left atrial Appendage (LAA) Closure with a WATCHMAN Device.

A: Multiplanar reconstruction is required for analysis as axial views are inadequate for assessing LAA dimensions given the shape and orientation of LAA. Measurements are made during the phase that corresponds best to maximal LAA end-diastolic filling (LV end-systolic filling). In multiplanar reformat (MPR) images, planes are aligned to the direction of the main lobe of the LAA. The orthogonal plane giving the LAA cross-section is moved to the level of the proximal left circumflex (LCx) artery.

B: Orthogonal (axial) cross-section ("end-on" view). Measurements of the maximal and minimal diameters, the area and perimeter of the LAA landing zone can be obtained.

$\mathrm{C}$ : The maximal length or depth of the LAA is measured from the landing zone to the distal tip of the main lobe (implant lobe) of the LAA in the longitudinal view (use largest value in coronal or sagittal view).

D: Volume rendered three-dimensional image obtained by cardiac computed tomography of the LAA showing a Windsock shape.

Perimeter-derived diameter is the most reproducible parameter for sizing an LAA occluder. It provides mean and maximum diameters of the landing zone and may improve correct device selection, resulting in less over- or undersizing [12-14].

For the ACP/Amulet, the size of the device is mostly based on the landing zone diameter, where the lobe will be anchored. The "anatomical" ostium is the plane that joins the left superior pulmonary vein rim (the ligament of Marshall) superiorly with the inferior junction of LA/LAA at the level of the left circumflex artery. The landing zone can be found $10 \mathrm{~mm}$ (for ACP) and $12 \mathrm{~mm}$ (for Amulet) below this segment, perpendicular to the major axis of the LAA, usually at the junction between the neck and the body of the LAA. The depth of the appendage is measured from the landing zone to the most distal tip of the main lobe of the appendage (Fig 3). For the WATCHMAN device, the LAA anatomical orifice diameter is measured on TOE at $0^{\circ}, 45^{\circ}, 90^{\circ}$ and $135^{\circ}$. The "effective" LAA orifice is defined as the plane connecting the pulmonary vein ridge superiorly $(1-2 \mathrm{~cm}$ within the left upper superior pulmonary vein ridge) to the inferior junction of the LA and the LAA at the level of the circumflex artery. The widest dimension should be used for sizing. Maximal length or depth of LAA is defined as the linear distance from the center of the landing zone to the distal tip of the main lobe of the appendage (Fig 4).

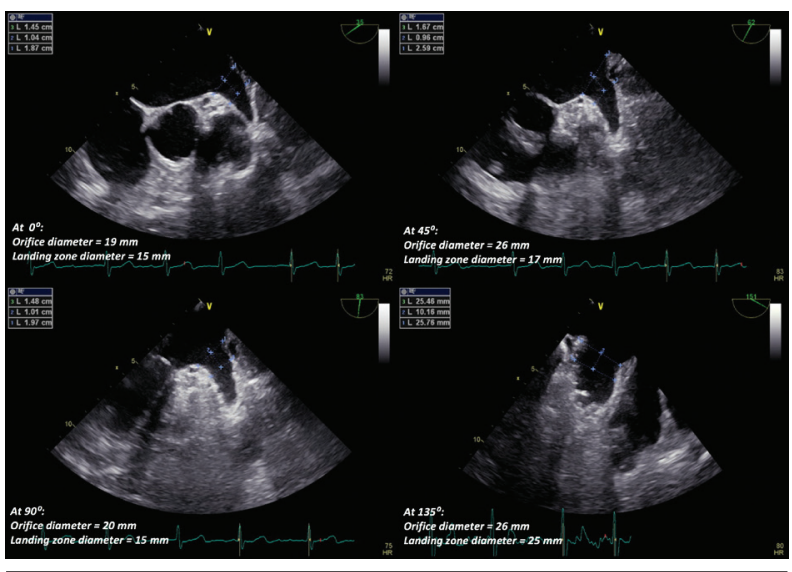

Figure 3: TOE evaluation of a patient before left atrial appendage (LAA) closure by the Amulet device. Images are acquired in the mid-oesophageal view focused on the LAA at $0^{\circ}$, at $45^{\circ}$ at $90^{\circ}$ and at $125-135^{\circ}$. Measurements are performed in a frame that gives the largest LAA, usually in end-systole. The orifice of the LAA is measured in each of these views. The landing zone (the part of the LAA in which the lobe of the Amulet device will be fixed) is measured in each of these views at $10-12 \mathrm{~mm}$ from the LAA orifice. The depth is measured in the main lobe of the LAA.

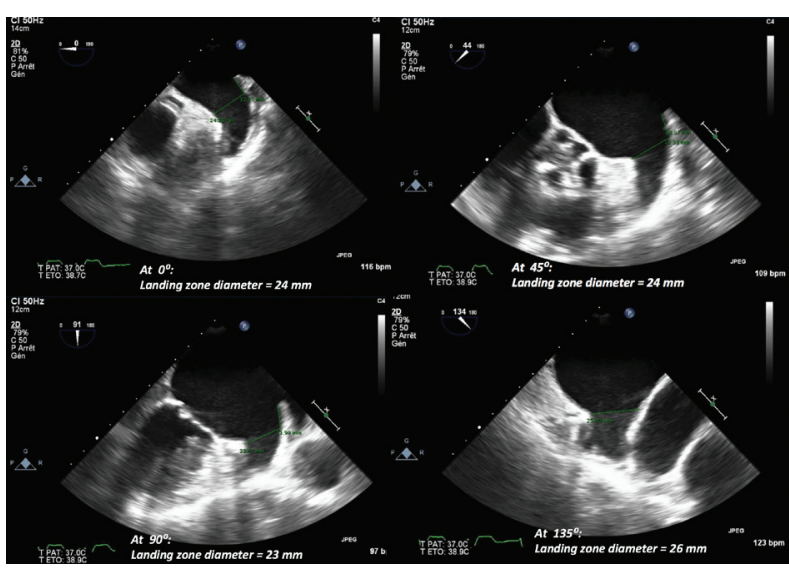

Figure 4: TOE images with measurements of the landing zone for left atrial appendage (LAA) closure with the WATCHMAN device at $0^{\circ}, 45^{\circ}, 90^{\circ}$ and $135^{\circ}$ views.

The shape of the LAA ostium is typically elliptical; other shapes have been less frequently described $[13,15]$. Markedly oval-shaped orifices or landing zones are associated with a significant difference between maximal and minimal diameters, which can be confounding and may lead to overor under-sizing. Manufacturers' recommendations for sizing are based on maximal diameter on TOE. The elliptical shape of LAA short-axis has led to the development of more flexible devices (last generation devices), allowing for more successful occlusion. The LAA usable depth is measured in the long-axis view from the LAA orifice to the LAA apex. On TOE, the angle of choice depends on LAA orientation. Angles of $0^{\circ}, 45^{\circ}$ or $90^{\circ}$ are typically used. In case of more

High quality figures are available as online supplements. 
laterally orientated LAA, angle of $90^{\circ}$ or more are necessary. On CCTA, the depth is best assessed on 3D MPR. The required depth is different between devices: ACP/Amulet devices need 10-12 $\mathrm{mm}$ to accommodate the lobe, WATCHMAN requires an equivalent depth as the diameter of the device.

In a study by Saw et al., fluoroscopy, 2D TOE and CCTA showed good correlations for LAA measurements. CT provided the largest measurements, followed by TOE and fluoroscopy [16]. In another study, LAA dimensions measured by CCTA correlated with the diameters obtained with fluoroscopy and intracardiac echocardiography (ICE), but they were slightly larger than the others [17]. A particular value of CCTA may be the detection and subsequent avoidance of gross sizing error by $2 \mathrm{D}$ TOE that occurred in a small proportion of cases (3.4\%) in a single-center registry [18]. In most studies, CCTA most often predicts the appropriate device size $[10,17,19]$. The use of real time 3D TOE for the visualization and quantitative analysis of LAA parameters is more frequent and has several advantages. RT3DTEE allows better spatial visualisation of the LAA and more comprehensive evaluation of the device and surrounding structures during the procedure. The use of MPR mode in 3D TOE allows correct identification and direct planimetric measurement of the LAA orifice area (Fig 5).

The measurements correlate well with those obtained with cardiac CT and are associated with a lower observer variability and higher accuracy and reliability than 2D TOE. Indeed, 2D TOE tends to significantly underestimate the maximal LAA orifice diameter compared to 3D TOE. There is a closer correlation between $3 \mathrm{D}$ TOE measurements and LAA closure device size than $2 \mathrm{D}$ TOE or angiographic measurements. After implantation, the device can be visualized more completely with 3D TOE [14, 20-23]. LAA is thought to have several functions, including acting as a reservoir during left ventricular systole. As such, LAA volume and sizes may vary with pressure and volume loading conditions. Typically, a minimal left atrial pressure of 10-15 $\mathrm{mmHg}$ is mandatory before final device sizing assessment. Intraprocedural volume loading with saline, aiming for a LA pressure $>12 \mathrm{mmHg}$, showed an increase in LAA dimensions in a small study [11].

\section{Morphology and Orientation}

The morphology of the LAA is extremely complex and heterogeneous. Individual LAA morphology is unique and may sometimes be referred to as a fingerprint. In more than two-thirds of the cases, LAA is composed of 2 or more lobes that may be located in different planes [24]. Early TOE anatomical studies described numerous shapes of LAA: narrow, tubular and hooked structure [25]. Currently used classification of LAA morphology is based on the general shape of the LAA. The four classical shapes are windsock (single dominant lobe without obvious bend), chicken wing (obvious bend in the body of the LAA), cactus (dominant central lobe with multiple secondary lobes) and cauliflower (short body with numerous secondary lobes and more complex internal characteristics) [13]. Different studies have evaluated a correlation between the thromboembolism risk and LAA morphological or structural features. LAA morphology has been shown to be a significant determinant of LAA flow

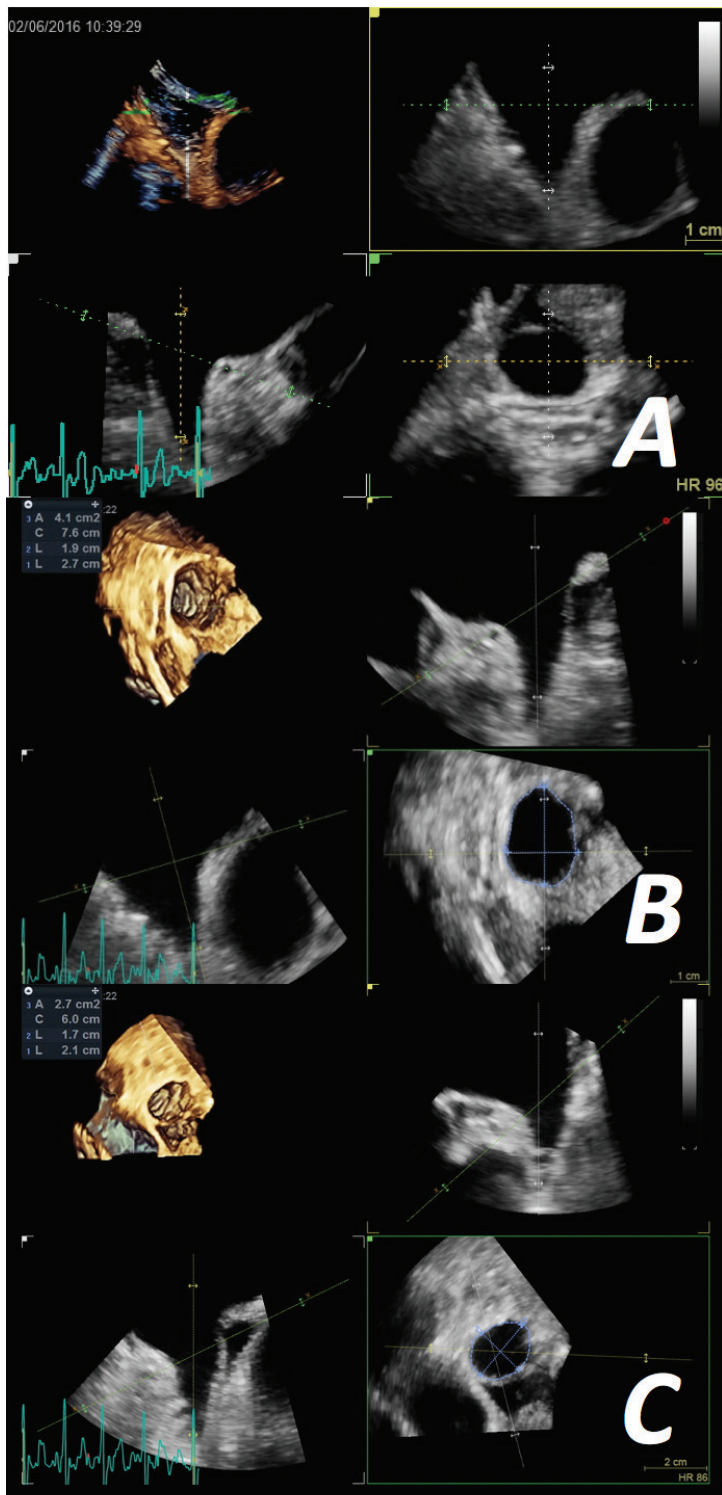

\section{Landing zone measurements: \\ Maximal diameter: $21 \mathrm{~mm}$ \\ Minimal aliameter: $17 \mathrm{~mm}$ \\ Perimeter-derived diameter: 19,1 $\mathrm{mm}$ \\ Area-derived: diameter: $18,5 \mathrm{~mm}$}

Figure 5: Step-by-step Real-time 3D TOE Evaluation for Left Atrial Appendage (LAA) Closure Device Sizing.

Step 1: In the frame with the largest LAA dimensions (usually end-systole), the first plane is positioned to transect the left circumflex (LCx) artery (this plane cuts the LAA showing the inferior and the superior walls of the LAA) and aligned to be parallel to the long-axis of the LAA.

Step 2: The second orthogonal plane is aligned with the long-axis of the LAA (Panel A).

Step 3: The third plane, the axial plane (green), is moved to be at the intersection of the LCx artery and the ridge of the left upper pulmonary vein. At this point the diameters of the LAA orifice can be measured (Panel B).

Step 4: The axial plane (green) is moved into the LAA to the estimated landing zone. The diameters of the landing zone can be measured in this view. (Panel C). For the WATCHMAN, this plane should transect the LCx artery and a point lower than the ridge but above the trabeculated parts of the LAA. For the Amulet-ACP, this plane is moved $10-12 \mathrm{~mm}$ into the LAA from the LAA ostium.

In our example, the measurements were made before Amulet implantation. The area-derived and perimeter-derived diameters were respectively 18.5 and $19.1 \mathrm{~cm}^{2}$. 
velocity, suggesting an underlying mechanism for the association between LAA morphology and embolic events [26]. Patients with chicken wing LAA morphology were shown to less likely develop an embolic event even after controlling for comorbidities and $\mathrm{CHADS}_{2}$ score [27]. This was confirmed in a recent meta-analysis [28]. Large LAA neck diameter and LAA depth as well as extensive LAA trabeculations may also be predictors of thromboembolic events [29].

Accurate assessment of the anatomic LAA characteristics is crucial before an LAA occlusion procedure as variations in LAA anatomy may impact device selection and procedure strategy. Understanding LAA morphology can help anticipating the complexity of the procedure and the need for the use of some unusual techniques. For example, the presence of a chicken wing morphology with an early and severe bend constitutes one of the most difficult anatomical settings for LAA occlusion. A particular implanting strategy has been described with the ACP-Amulet device and consists of deploying the distal lobe of the device inside the chicken-wing bend ('Sandwich' technique) [30]. However, in some very complex chicken wing configuration or in case of very shallow LAA, the anatomy may be judged as inappropriate for LAA closure. Determination of LAA orientation also has procedural implications. Most LAA are orientated superior-anteriorly. For this reason, most LAA occlusion procedures are performed with the so called double-curve sheaths (double-curve access sheath for WATCHMAN, Boston Scientific; TV45x45 for ACP/ Amulet, Saint-Jude Medical/Abbott). In cases of LAA oriented infero-posteriorly, a single-curve may be preferred [13].

Images obtained by volume rendered (VR) 3D CCTA can also be useful to plan the procedure. With manipulation of VR images, it is possible to determine the best corresponding fluoroscopic views to guide LAA occlusion during the procedure. The choice of the fluoroscopic views during the procedure relies on the LAA anatomy and on the device selected for the occlusion. The right anterior oblique (RAO) view with cranial projection ( $\mathrm{RAO} 20-30^{\circ}$, cranial 20-30 $)$ identifies the left lateral ridge and shows the orifice and proximal segment of the LAA best, which is particularly useful for ACP/Amulet implantation. On TOE, this view corresponds usually to the $45^{\circ}$ view. The RAO view with caudal projection ( $\mathrm{RAO} 20-30^{\circ}$, Caudal $20-30^{\circ}$ ), corresponding to the $135^{\circ}$ view on TOE, can separate the possible anterior and posterior lobes and shows the body and distal segment of the LAA, which is useful for sheath placement in the distal lobe and for WATCHMAN deployment. As in transcatheter aortic valve implantation, CCTA can help planning the precise fluoroscopic implant angle.

\section{Transseptal Puncture}

Transseptal puncture is performed under fluoroscopy. Left anterior oblique view $\left(30^{\circ}\right)$ is preferred as the transseptal needle is located perpendicular to the septum in this view when oriented at about $45^{\circ}$ medially and posteriorly (clockwise, 4-6 o'clock orientation). After a first drop from the superior vena cava to the right atrium (RA) wall, the second drop confirms needle position in the fossa ovalis. TOE is useful for the transseptal puncture guidance as it allows targeting the infero-posterior region of the septum to perform the puncture (Figure 6).

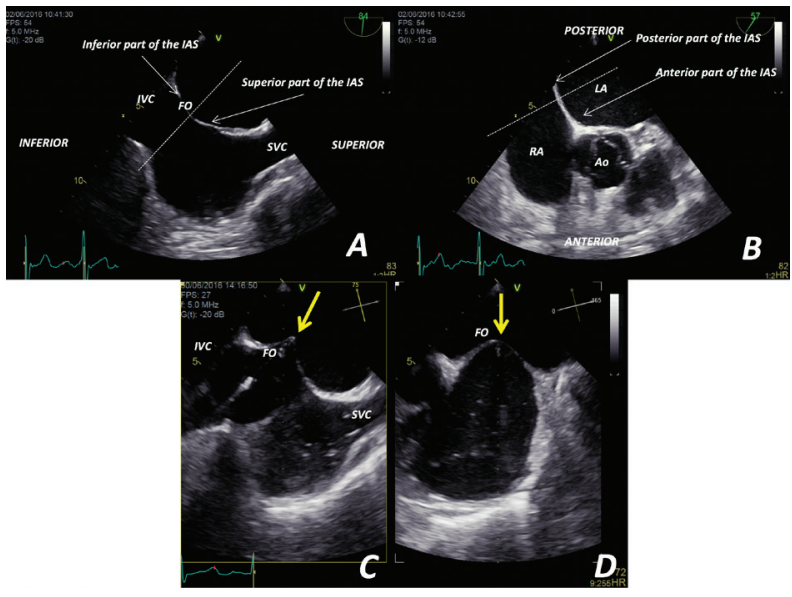

Figure 6: A: Bicaval view $\left(90^{\circ}\right)$ with the superior vena cava (SVC) on the right and inferior vena cava (IVC) on the left. The fossa ovalis (FO), the site of puncture, is imaged with its superior (close to the SVC) and inferior (close to the IVC) aspects.

B: Short-axis view $\left(45^{\circ}\right)$ showing the aorta as a landmark. The FO is also visualized with its anterior (close to the aortic valve (Ao)) and posterior (close to the atrial roof) aspects.

C: Using bi-plane imaging with a 3D-TOE probe, the bicaval view shows the tenting of the FO (arrow) that results from impinging of the Brokenbrough needle into the FO.

$\mathrm{D}$ : The orthogonal plane (short-axis) is set through the tenting point to image the tenting on the FO from the antero-posterior aspect of the FO. The optimal area for puncture for LAA occlusion is the infero-posterior region of the interatrial septum.

Abbreviations: IAS: inter-atrial septum; LA: left atrium; RA: right atrium; SVC: superior vena cava.

Simultaneous TOE images demonstrate tenting of the inter-atrial septum (IAS) due to pressure from the needle prior to the puncture. In the upper oesophageal position, the bicaval view $\left(90-110^{\circ}\right)$ assesses the height of the puncture, while the short-axis view $\left(30-60^{\circ}\right)$ gives information about the antero-posterior position and allows puncture to be away from the aorta. As mentioned, ideal puncture location lies in the infero-posterior region of the IAS as it facilitates coaxial orientation of the access sheath for accessing the LAA. TOE can identify features that may be associated with complex transseptal puncture (thick IAS, very enlarged LA, aneurysmal IAS) and can therefore change procedural strategy (use of radiofrequency transseptal needle, increased transseptal needle curve...).

\section{Successful Implantation}

After implantation, evaluation of the success of the implantation and the absence of complications are of utmost importance. TOE remains the gold-standard imaging modality for assessing the success of the implantation but fluoroscopy is complimentary. For the WATCHMAN, the PASS criterion should be achieved: Position (device is distal to or at the ostium of the LAA), Anchor (device is stable, fixation anchors engaged, tug test stability), Size (device is compressed 8-20\% of original size), Seal (device spans ostium, all lobes of LAA are covered, peri-device leak $<5 \mathrm{~mm}$ ). For the ACP/Amulet device, 5 criteria are used to 
assess implantation adequacy: (1) tire-shape of the lobe, (2) separation of the lobe from the disc, 3 ) concavity of the disc, (4) axis of the lobe is perpendicular to the neck axis at landing zone, (5) lobe (at least 2 thirds) lies adequately within the circumflex artery. The disc should cover completely the anatomical orifice of the LAA. Gentle traction is applied to the disc and maintained for 30 seconds to confirm stability. The absence of significant peri-device leaks is assessed by TOE in all incidences (by color flow Doppler with Nyquist limit $\left.<50 \mathrm{~cm} \cdot \mathrm{s}^{-1}\right)$ (Fig 7, panel A).

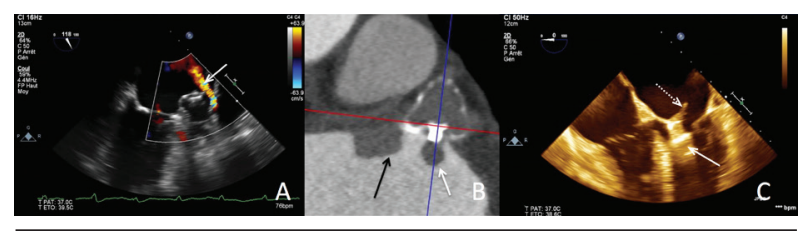

Figure 7: Evaluation of Implantation Success and Complications After LAA Occlusion.

A: Perprocedural Color flow Doppler TOE imaging showing peri-device leak (arrow) after WATCHMAN implantation.

B: Contrast-enhanced CT images revealing an atrial-side device thrombus on a WATCHMAN device at the fabric insert (white arrow) and adjacent to the device (black arrow).

Reproduced with permission from Cardiac CT angiography for device surveillance after endovascular left atrial appendage closure; Saw et al.; European Heart Journal Cardiovascular Imaging; 2015;16:1198-206. doi: 10.1093/ehjci/jev067. Oxford University Press.

C: Delayed embolization of an Amplatzer Cardiac Plug. TOE image showing entrapment of the device (arrow) in the anterior mitral apparatus with flail leaflet (dotted arrow).

CCTA can also detect peri-device leaks and identify the underlying mechanism. Different aetiologies explain peri-device leaks. In WATCHMAN cases, leaks are mostly eccentric and secondary to an edge effect. For ACP/Amulet cases, higher proportion of off-axis lobes were found in cases of patent LAA $[31,32]$ and leaks were more frequent when lobe compression was $\leq 10 \%$ [33]. In the presence of peri-device leak $\geq 5 \mathrm{~mm}$, resuming or pursuing antithrombotic therapy or further intervention may be considered. However, the clinical impact of peri-device leak is unknown with no clear relationship with adverse events [3, 4, 34].

\section{Thrombus}

The rationale for LAA closure development was that around $90 \%$ of thrombi in the LA originated in the LAA in patients with non-valvular AF after evaluation by autopsy, TOE or operation [35]. In AF patients, LAA structure and function have several characteristics that make LAA a prothrombotic milieu favouring thrombus formation. The elements of the Virchow's triad are found in this setting: blood stasis in this blind-ended pouch with trabeculations and electromechanical dysfunction [36, 37], endothelial dysfunction (secondary to fibrosis and inflammation) [38]. and prothrombotic state (linked to the activation of coagulation cascade) $[39,40]$. The presence of thrombus is usually considered as an absolute contra-indication for LAA closure, even though several cases of LAA occlusion with Amulet have been described [41, 42]. The standard of best practice recommends anticoagulation treatment for at least 3-4 weeks in case of detection of thrombus in the LAA [6]. Control imaging after this period to confirm thrombus resolution is recommended before procedure planning. Left atrial (LA) thrombus on TOE is recognized as an echo dense mass, with smooth contours and synchronous movement with adjacent heart wall during heart cycle. TOE is considered the gold standard modality in detecting LA or LAA thrombi. In one intraoperative study, TOE was compared with direct visualization of LA contents at surgery and had a sensitivity and specificity of $100 \%$ and $99 \%$, respectively [43] 3D TOE can help discriminate pectinate muscles from thrombus in cases with diagnostics doubts [44]. In case of uncertainty about the presence of a thrombus in the LAA, the use of ultrasound contrast can be helpful [45].

Studies with mutlidetector CT have reported good sensitivity and specificity for CCTA for LAA thrombus detection $[46,47]$. Recent meta-analysis demonstrated that CT shows a good diagnostic accuracy in detecting LA/ LAA thrombus with high sensitivity and specificity [48, 49]. This technique has a high negative predictive value for excluding LAA thrombus. Adaptation to CCTA protocols may improve LAA thrombus detection: delayed imaging (2-phase scan with delayed image acquisition at least 30 seconds after contrast bolus), dual-enhanced scan (single scan after 2-bolus contrast), dual-energy source and prone position $[50,51]$. When delayed imaging was performed, the diagnostic accuracy significantly improved across different studies [49]. Hence, CCTA, particularly when delayed imaging is performed, may be a reliable alternative for the detection of LA or LAA thrombi. Thrombus appears in this setting as round-shaped or oval filling defects (Fig 7, panel B).

The presence of DAT is assessed during post-procedural device surveillance. DAT is not rare, with an overall reported rate of $3.9 \%$ in a recent review [52]. Diagnosis is most of the time performed during routine follow-up imaging, as most cases remain asymptomatic. Management consist mostly on short-term anticoagulation. Recently, Main et al. have proposed consensus echocardiographic diagnostic criteria for DAT diagnosis: echo density on the LA aspect of the device (1) not explained by imaging artefact; (2) inconsistency with normal healing/device incorporation; (3) visible in multiple TOE planes, (4) in contact with the LAA occluder device; and (5) exhibiting independent motion [53]. CCTA is also able to detect DAT or thrombus on the adjacent LA wall [32].

\section{Complications}

Device embolization is a well-known and feared complication of LAA closure with an average reported rate of less than $4 \%$ [54], and less than $1 \%$ in recent registries [3, 4]. In a systematic review by Aminian et al., two-thirds of reported cases were acute, with $60 \%$ of those cases occurring during the procedure. Most cases were asymptomatic [55]. Device embolization may be diagnosed by fluoroscopy, chest X-ray, TTE, TOE or CCTA (Fig 7, panel C). Pericardial effusion incidence is decreasing with last generation of devices, standardization and better understanding of the procedure [2]. Pericardial effusion occurs mostly 
during the procedure and is best diagnosed by echocardiography. Pericardiocentesis is rarely necessary and can be echo-guided.

\section{ALTERNATIVE AND FUTURE IMAGING MO- DALITIES}

\section{Intracardiac Echocardiography (ICE)}

With a successful ICE-guided LAA closure reported rate $\geq$ $97 \%$, ICE has proved to be a valid alternative imaging modality for LAA occlusion in experienced centers [56-59]. The main advantage of ICE utilization is that it avoids the need for general anaesthesia or deep sedation, which can be associated with additional complications (aspiration, delirium...), lead to longer procedure-time and to additional resource utilization. Of note, a recent small study showed the feasibility of LAA closure using conscious sedation with TOE guidance [60] whereas another study described the use of an ICETOE probe through the oesophageal route without general anaesthesia for the monitoring of ACP device implantation [61]. ICE currently lacks multiplanar capabilities and may provide suboptimal imaging of LAA, even though the ability to move the probe in different positions may compensate these shortcomings. Furthermore, location of the ICE probe within the LA cavity improves imaging of the LAA. The main disadvantages of ICE remain the additional cost and a significant learning curve. Several ICE catheters are commercially available including the AcuNav ultrasound catheter (Siemens Medical Solutions, USA, Inc., Mountain View, CA, USA) and the ViewFlex Xtra catheter (St. Jude Medical/Abbott). Both systems are available in 8-10 Fr size and can be steered in 4 directions (anterior, posterior, left, and right). They also have color flow and spectral Doppler capabilities. The catheters are inserted from the ipsilateral or contralateral femoral vein via large venous sheaths and advanced from the inferior vena cava to the working position. The ICE probe can be positioned in the RA, the coronary sinus [56], the pulmonary artery [62] or the LA via a single-transseptal approach or after a second transseptal puncture [57]. Once the desired position is achieved, the probe can be set in that position with a lock mechanism. ICE can provide detailed imaging of the LAA in multiple views with serial and real-time assessment of the procedures steps (Fig 8).

ICE guidance is able to achieve tasks typically performed by TOE: evaluation of the presence of thrombus [63]; transseptal puncture guidance [64] measurement of LAA dimension for device sizing [17]; verification of the delivery sheath position; evaluation of device stability and peri-device leaks and continuous monitoring to detect procedural complications [56].

\section{Integrated/Synchronized X-Ray and Echocardiog- raphy (Fusion Imaging)}

LAA occlusion procedures under fluoroscopic and echocardiographic guidance with image fusion technology have been described with good results [65]. The EchoNavigator ${ }^{\circledR}$-system (Philips, Best, The Netherlands) is based on a fast and automated image based algorithm that localizes and tracks the TOE probe. Since the 3D dataset generated by the TOE probe has a known spatial relationship to the TOE probe, once the algorithm has recognized the TOE probe and its orientation, TOE images and X-Ray are co-registered and synchronized in real-time (Fig 9) [66].

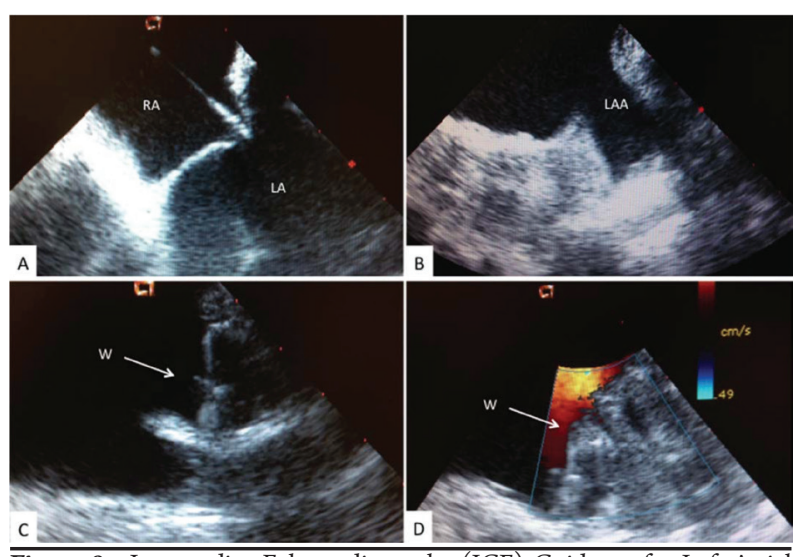

Figure 8: Intracardiac Echocardiography (ICE) Guidance for Left Atria Appendage (LAA) Occlusion. (A) Interatrial septal puncture (ICE probe in the right atrium); (B) visualization of the LAA and anatomy assessment (ICE probe in the left atrium); (C) device position assessment; (D) check for peri-device flow/leak with color Doppler flow imaging.

Abbreviations: LA: left atrium; RA: right atrium; W: WATCHMAN device. Reproduced with permission from Intracardiac versus transesophageal echocardiography for left atrial appendage occlusion with watchman; Frangieh et al.; Catheterization and Cardiovascular Interventions; 2016. doi: 10.1002/ ccd.26805. Wiley Periodicals, Inc.

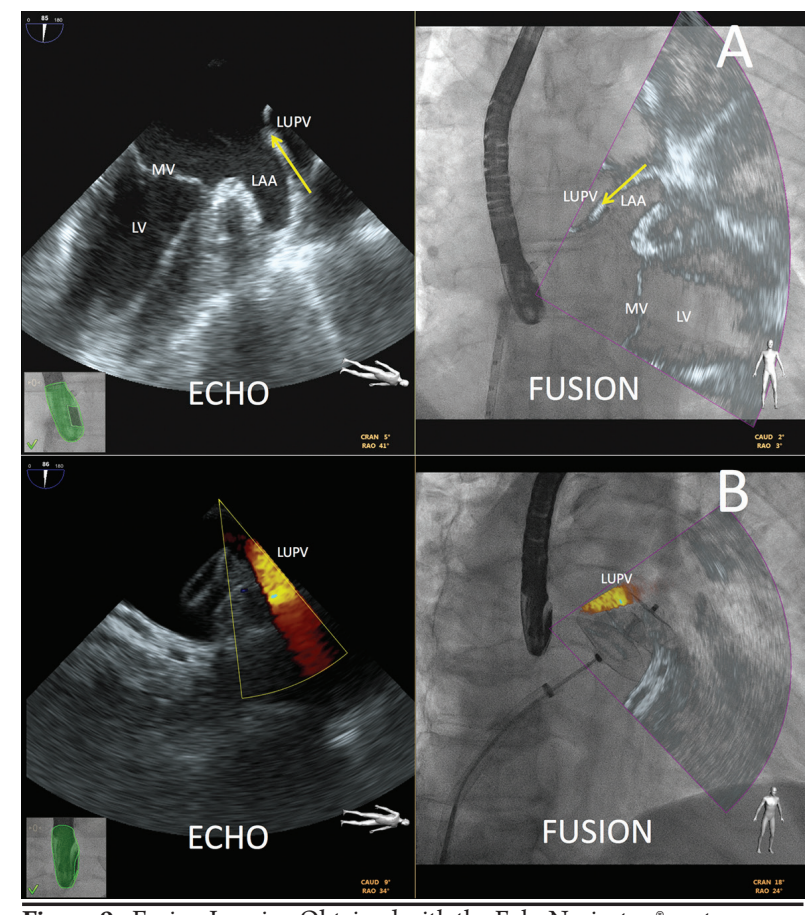

Figure 9: Fusion Imaging Obtained with the EchoNavigator ${ }^{\circledR}$-system.

A: Fusion of the TOE image (left) with the fluoroscopy image (right) showing the left atrial appendage (LAA) and surrounding structures. This imaging modality allows identification of the position of the Coumadin ridge (yellow arrow) and facilitates positioning of the sheath in the LAA.

B: Fusion of the Color flow Doppler TOE image (left) with the fluoroscopy image showing the absence of obstruction to flow in the left upper pulmonary vein (LUPV). The stability of the device (Amulet) is tested with application of slight tension on the delivery cable (wiggle test).

Abbreviations: LSPV: left superior pulmonary vein; LV: left ventricle; MV: mitral valve. 
The system allows the simultaneous display of up to 3 different echo views: 1 ) the $\mathrm{C}$-arm gantry view, in which the echo view is oriented in the same anatomic alignment as the $\mathrm{x}$-ray view and automatically updated by each movement of the $\mathrm{C}$-arm gantry; this image is then fused with the $\mathrm{X}$-ray view and both images are concordant in size and orientation; 2) the « echo » view, which is the standard TOE projection showing up on the echo machine; and 3) a free image that can be rotated or cropped by the operator at the table site by using a sterile mouse pad. This view allows the operator to manipulate the real-time images without the need to request further TOE projections. There is also a marker feature that allows setting markers on anatomical location of interest on the echo image that are automatically displayed on the X-Ray image. This imaging modality seems useful for the transseptal puncture and for sheath and device positioning. This technology has the potential to improve the interaction between the operator and the imager. Whether this imaging modality may increase safety, accuracy, and efficacy of LAA occlusion has yet to be demonstrated. Of note, a preliminary study showed a significant reduction in radiation dose and fluoroscopy time with the use of the EchoNavigator ${ }^{\circledast}$-system [67].

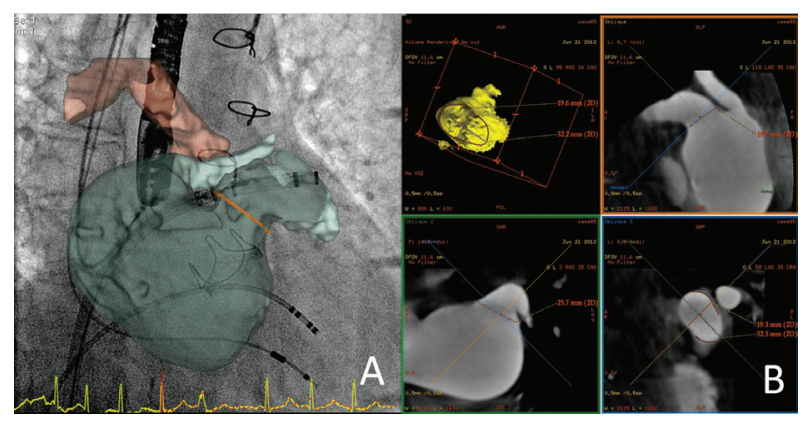

Figure 10: Images Obtained After Rotational Angiography. A: RAO $20^{\circ}$ view. The left atrium (LA) and left atrial appendage (LAA) are cut away along the viewing angle (i.e. $20^{\circ}$ from frontal), the posterior wall of the structures is visible (green). A line is drawn at the position where the LAA neck is measured (orange). The bronchi (blue) are segmented to verify positioning of the $3 \mathrm{D}$ model. The Watchman Delivery System (WDS) is positioned in the LAA, with the device still in the sheath. Markers on the WDS allow verification of adequate LAA length.

B: 3D reconstruction of LAA (left upper corner). The LA is cut away; viewing angle is from inside the LA into the LAA ostium. Right lower corner shows cross-section at the LAA ostium with measurements. Both other images show level where cross-section was created (blue lines).

\section{Rotational Angiography}

Rotational angiography (3DRA) is an innovative method that allows per-procedural reconstruction of tomographic slices of a volume of interest in a manner similar to CT, using singe plane radiographic equipment $[68,69]$. These slices can be used to perform measurements in any plane of the $3 \mathrm{D}$ volume, or to make a $3 \mathrm{D}$ reconstruction of a structure of interest and integrate it with fluoroscopy or other 3D mapping technologies. In the setting of LAA closure, the technology can be leveraged to create near-real time 3D models of the LAA. These models provide anatomical guidance by overlaying the model on the live 2D fluoroscopy image. Using tools typi- cally provided by the manufacturer of the X-Ray equipment, the 3D model can be appropriately sized and positioned on the $2 \mathrm{D}$ image, and rotates automatically with the angle of the imaging tube to provide the correct visualization (Fig 1). In addition, a multiplanar reconstruction can be made through any arbitrary angle, such that a planar slice can be created at the base of the appendage perpendicular to the long-axis of the appendage in that position. This slice can be used to measure the exact dimensions of the base of the LAA without imaging imperfections that may be present with TOE in certain anatomies (Fig 2 or Fig 3 or both). Preliminary data suggest this workflow may offer more accurate selection of the most appropriate LAA occluder size (unpublished data).

\section{CONCLUSIONS}

Imaging has a key role in every step of LAA occlusion: pre-procedural planning, procedural guidance and post-implantation surveillance. Several imaging modalities are available and offer complementary information, allowing good understanding of the LAA anatomy and its relationship to the surrounding structures. Multimodality imaging should be used to improve procedural safety and efficacy of LAA occlusion.

\section{CONFLICTS OF INTEREST}

Dr. Lempereur, Dr. Dulgheru, and Dr Lancellotti have no disclosure. Dr. Aminian is proctor for St Jude Medical/Abbott and Boston Scientific. Dr. De Potter is proctor for Boston Scientific.

\section{REFERENCES}

1. Holmes DR, Reddy VY, Turi ZG, Doshi SK, Sievert H, Buchbinder $\mathrm{M}$, et al. Percutaneous closure of the left atrial appendage versus warfarin therapy for prevention of stroke in patients with atrial fibrillation: a randomised non-inferiority trial. Lancet. 2009;374(9689):534-42. DOI: 10.1016/S0140-6736(09)61343-X PMID: 19683639

2. Holmes DR, Jr., Kar S, Price MJ, Whisenant B, Sievert H, Doshi $\mathrm{SK}$, et al. Prospective randomized evaluation of the Watchman Left Atrial Appendage Closure device in patients with atrial fibrillation versus long-term warfarin therapy: the PREVAIL trial. J Am Coll Cardiol. 2014;64(1):1-12. DOI: 10.1016/j.jacc.2014.04.029 PMID: $\underline{24998121}$

3. Tzikas A, Shakir S, Gafoor S, Omran H, Berti S, Santoro G, et al. Left atrial appendage occlusion for stroke prevention in atrial fibrillation: multicentre experience with the AMPLATZER Cardiac Plug. EuroIntervention. 2016;11(10):1170-9. DOI: 10.4244/EIJY15M01 06 PMID: 25604089

4. Boersma LV, Schmidt B, Betts TR, Sievert H, Tamburino C, Teiger $\mathrm{E}$, et al. Implant success and safety of left atrial appendage closure with the WATCHMAN device: peri-procedural outcomes from the EWOLUTION registry. Eur Heart J. 2016;37(31):2465-74. DOI: 10.1093/eurheartj/ehv730 PMID: 26822918

5. Kirchhof P, Benussi S, Kotecha D, Ahlsson A, Atar D, Casadei B, et al. 2016 ESC Guidelines for the management of atrial fibrillation developed in collaboration with EACTS. Eur J Cardiothorac Surg. 2016;50(5):e1-e88. DOI: 10.1093/ejcts/ezw313 PMID: 27663299 6. January CT, Wann LS, Alpert JS, Calkins H, Cigarroa JE, Cleveland JC, Jr., et al. 2014 AHA/ACC/HRS guideline for the management of patients with atrial fibrillation: a report of the American College of Cardiology/American Heart Association Task Force on Practice Guidelines and the Heart Rhythm Society. J Am Coll Cardiol. 2014;64(21):e1-76. DOI: 10.1016/j.jacc.2014.03.022 PMID: 24685669

7. Freixa X, Chan JL, Tzikas A, Garceau P, Basmadjian A, Ibrahim R. The Amplatzer Cardiac Plug 2 for left atrial appendage occlu- 
sion: novel features and first-in-man experience. EuroIntervention. 2013;8(9):1094-8. DOI: 10.4244/EIJV8I9A167 PMID: 23339815

8. Sick PB, Schuler G, Hauptmann KE, Grube E, Yakubov S, Turi ZG, et al. Initial worldwide experience with the WATCHMAN left atrial appendage system for stroke prevention in atrial fibrillation. J Am Coll Cardiol. 2007;49(13):1490-5. DOI: 10.1016/i.jacc.2007.02.035 PMID: 17397680

9. Saw J, Lopes JP, Reisman M, McLaughlin P, Nicolau S, Bezerra HG. Cardiac Computed Tomography Angiography for Left Atrial Appendage Closure. Can J Cardiol. 2016;32(8):1033 e1-9. DOI: 10.1016/i.cica.2015.09.020 PMID: 26907169

10. Wang DD, Eng M, Kupsky D, Myers E, Forbes M, Rahman M, et al. Application of 3-Dimensional Computed Tomographic Image Guidance to WATCHMAN Implantation and Impact on Early Operator Learning Curve: Single-Center Experience. JACC Cardiovasc Interv. 2016;9(22):2329-40. DOI: 10.1016/i.jcin.2016.07.038 PMID 27884358

11. Spencer RJ, Tsang MY, Saw J, Fahmy P, Gin K, Jue J, et al. TCT-725 Changes in left atrial appendage dimensions following volume loading during percutaneous left atrial appendage closure. J Am Coll Cardiol. 2015;66(15):B296. DOI: 10.1016/i.jacc.2015.08.746

12. van Rosendael PJ, Katsanos S, van den Brink OW, Scholte AJ, Trines SA, Bax JJ, et al. Geometry of left atrial appendage assessed with multidetector-row computed tomography: implications for transcatheter closure devices. EuroIntervention. 2014;10(3):364-71. DOI: 10.4244/EIJV10I3A62 PMID: 24273250

13. Wang Y, Di Biase L, Horton RP, Nguyen T, Morhanty P, Natale A. Left atrial appendage studied by computed tomography to help planning for appendage closure device placement. J Cardiovasc Electrophysiol. 2010;21(9):973-82. DOI: $10.1111 / \mathrm{j} .1540-8167.2010 .01814 . \mathrm{x}$ PMID: 20550614

14. Al-Kassou B, Tzikas A, Stock F, Neikes F, Volz A, Omran H. A comparison of two-dimensional and real time 3D transesophageal echocardiography and angiography for assessing the left atrial appendage anatomy for sizing a left atrial appendage occlusion system - impact of volume loading. EuroIntervention. 2016. DOI: 10.4244/ EIJ-D-15-00543 PMID: 27973328

15. Su P, McCarthy KP, Ho SY. Occluding the left atrial appendage: anatomical considerations. Heart. 2008;94(9):1166-70. DOI: 10.1136 hrt.2006.111989 PMID: 17488765

16. Saw J, Fahmy P, Spencer R, Prakash R, McLaughlin P, Nicolaou S et al. Comparing Measurements of CT Angiography, TEE, and Fluoroscopy of the Left Atrial Appendage for Percutaneous Closure. J Cardiovasc Electrophysiol. 2016;27(4):414-22. DOI: 10.1111/ jce.12909 PMID: 26728988

17. Clemente A, Avogliero F, Berti S, Paradossi U, Jamagidze G, Rezzaghi $\mathrm{M}$, et al. Multimodality imaging in preoperative assessment of left atrial appendage transcatheter occlusion with the Amplatzer Cardiac Plug. Eur Heart J Cardiovasc Imaging. 2015;16(11):1276-87. DOI; 10.1093/ehjci/jev097 PMID: 25916628

18. Rajwani A, Nelson AJ, Shirazi MG, Disney PJ, Teo KS, Wong DT, et al. CT sizing for left atrial appendage closure is associated with favourable outcomes for procedural safety. Eur Heart J Cardiovasc Imaging 2016. DOI: 10.1093/ehjci/jew212 PMID: 28013284

19. Lopez-Minguez JR, Gonzalez-Fernandez R, Fernandez-Vegas C, Millan-Nunez V, Fuentes-Canamero ME, Nogales-Asensio JM, et al Comparison of imaging techniques to assess appendage anatomy and measurements for left atrial appendage closure device selection. J In vasive Cardiol. 2014;26(9):462-7. PMID: 25198490

20. Goebel B, Wieg S, Hamadanchi A, Otto S, Jung C, Kretzschmar D, et al. Interventional left atrial appendage occlusion: added value of $3 \mathrm{D}$ transesophageal echocardiography for device sizing. Int J Cardiovasc Imaging. 2016;32(9):1363-70. DOI: 10.1007/s10554-016-0923-Z PMID: 27271934

21. Bai W, Chen Z, Tang H, Wang H, Cheng W, Rao L. Assessment of the left atrial appendage structure and morphology: comparison of real-time three-dimensional transesophageal echocardiography and computed tomography. Int J Cardiovasc Imaging. 2016. DOI: 10.1007/s10554-016-1044-4 PMID: 28012051

22. Nucifora G, Faletra FF, Regoli F, Pasotti E, Pedrazzini G, Moccetti T, et al. Evaluation of the left atrial appendage with real-time 3-dimensional transesophageal echocardiography: implications for catheter-based left atrial appendage closure. Circ Cardiovasc Imaging 2011;4(5):514-23. DOI: 10.1161/CIRCIMAGING.111.963892 PMID: 21737601

23. Kumar V, Nanda NC. Is it time to move on from two-dimensional transesophageal to three-dimensional transthoracic echocardiography for assessment of left atrial appendage? Review of existing literature. Echocardiography. 2012;29(1):112-6. DOI: 10.1111/j.15408175.2011.01535.x PMID: 23186295

24. Veinot JP, Harrity PJ, Gentile F, Khandheria BK, Bailey KR, Eickholt JT, et al. Anatomy of the normal left atrial appendage: a quantitative study of age-related changes in 500 autopsy hearts: implications for echocardiographic examination. Circulation. 1997;96(9):3112-5. PMID: 9386182

25. Ernst G, Stollberger C, Abzieher F, Veit-Dirscherl W, Bonner E, Bibus B, et al. Morphology of the left atrial appendage. Anat Rec. 1995;242(4):553-61. DOI: 10.1002/ar.1092420411 PMID: 7486025

26. Fukushima K, Fukushima N, Kato K, Ejima K, Sato H, Fukushima $\mathrm{K}$, et al. Correlation between left atrial appendage morphology and flow velocity in patients with paroxysmal atrial fibrillation. Eur Heart Cardiovasc Imaging. 2016;17(1):59-66. DOI: 10.1093/ehjci/jev117 PMID: 25944049

27. Di Biase L, Santangeli P, Anselmino M, Mohanty P, Salvetti I, Gili S et al. Does the left atrial appendage morphology correlate with the risk of stroke in patients with atrial fibrillation? Results from a multicenter study. J Am Coll Cardiol. 2012;60(6):531-8. DOI: 10.1016/i. jacc.2012.04.032 PMID: 22858289

28. Lupercio F, Carlos Ruiz J, Briceno DF, Romero J, Villablanca PA, Berardi $\mathrm{C}$, et al. Left atrial appendage morphology assessment for risk stratification of embolic stroke in patients with atrial fibrillation: A meta-analysis. Heart Rhythm. 2016;13(7):1402-9. DOI: 10.1016/j. hrthm.2016.03.042 PMID: 27016474

29. Khurram IM, Dewire J, Mager M, Maqbool F, Zimmerman SL, Zipunnikov V, et al. Relationship between left atrial appendage morphology and stroke in patients with atrial fibrillation. Heart Rhythm. 2013;10(12):1843-9. DOI: 10.1016/j.hrthm.2013.09.065 PMID: 24076444

30. Freixa X, Tzikas A, Basmadjian A, Garceau P, Ibrahim R. The chicken-wing morphology: an anatomical challenge for left atrial appendage occlusion. J Interv Cardiol. 2013;26(5):509-14. DOI: 10.1111 joic.12055 PMID: 24033805

31. Pillarisetti J, Reddy YM, Gunda S, Swarup V, Lee R, Rasekh A, et al. Endocardial (Watchman) vs epicardial (Lariat) left atrial appendage exclusion devices: Understanding the differences in the location and type of leaks and their clinical implications. Heart Rhythm. 2015;12(7):1501-7. DOI: 10.1016/j.hrthm.2015.03.020 PMID: 25778430

32. Saw J, Fahmy P, DeJong P, Lempereur M, Spencer R, Tsang M, et al. Cardiac CT angiography for device surveillance after endovascular left atrial appendage closure. Eur Heart J Cardiovasc Imaging. 2015;16(11):1198-206. DOI: 10.1093/ehjci/jev067 PMID: 25851318

33. Jaguszewski M, Manes C, Puippe G, Salzberg S, Muller M, Falk $\mathrm{V}$, et al. Cardiac CT and echocardiographic evaluation of peri-device flow after percutaneous left atrial appendage closure using the AMPLATZER cardiac plug device. Catheter Cardiovasc Interv. 2015;85(2):306-12. DOI: 10.1002/ccd.25667 PMID: 25205611

34. Viles-Gonzalez JF, Kar S, Douglas P, Dukkipati S, Feldman T, Horton $\mathrm{R}$, et al. The clinical impact of incomplete left atrial appendage closure with the Watchman Device in patients with atrial fibrillation: a PROTECT AF (Percutaneous Closure of the Left Atrial Appendage Versus Warfarin Therapy for Prevention of Stroke in Patients With Atrial Fibrillation) substudy. J Am Coll Cardiol. 2012;59(10):923-9. DOI: 10.1016/j.jacc.2011.11.028 PMID: 22381428

35. Blackshear JL, Odell JA. Appendage obliteration to reduce stroke in cardiac surgical patients with atrial fibrillation. Ann Thorac Surg. 1996;61(2):755-9. DOI: 10.1016/0003-4975(95)00887-X PMID: $\underline{8572814}$

36. Takada T, Yasaka M, Nagatsuka K, Minematsu K, Yamaguchi T Blood flow in the left atrial appendage and embolic stroke in nonvalvular atrial fibrillation. Eur Neurol. 2001;46(3):148-52. DOI: 50788 PMID: 11598333

37. Garcia-Fernandez MA, Torrecilla EG, San Roman D, Azevedo J, Bueno $\mathrm{H}$, Moreno MM, et al. Left atrial appendage Doppler flow patterns: implications on thrombus formation. Am Heart J. 1992;124(4):955 61. DOI: 10.1016/0002-8703(92)90978-5 PMID: 1529906

38. Frustaci A, Chimenti C, Bellocci F, Morgante E, Russo MA, Maseri A. Histological substrate of atrial biopsies in patients with lone atrial fibrillation. Circulation. 1997;96(4):1180-4. PMID: 9286947

39. Inoue H, Nozawa T, Okumura K, Jong-Dae L, Shimizu A, Yano K 
Prothrombotic activity is increased in patients with nonvalvular atrial fibrillation and risk factors for embolism. Chest. 2004;126(3):68792. DOI: $10.1378 /$ chest.126.3.687 PMID: 15364743

40. Watson T, Shantsila E, Lip GY. Mechanisms of thrombogenesis in atrial fibrillation: Virchow's triad revisited. Lancet. 2009;373(9658):15566. DOI: 10.1016/S0140-6736(09)60040-4 PMID: 19135613

41. Aytemir K, Aminian A, Asil S, Canpolat U, Kaya EB, Sahiner L, et al. First case of percutaneous left atrial appendage closure by amulet device in a patient with left atrial appendage thrombus. Int J Cardiol. 2016;223:28-30. DOI: 10.1016/j.ijcard.2016.08.171 PMID: $\underline{27529584}$

42. Jalal Z, Iriart X, Dinet ML, Selly JB, Tafer N, Renou P, et al. Extending percutaneous left atrial appendage closure indications using the AMPLATZER Cardiac Plug device in patients with persistent left atrial appendage thrombus: The thrombus trapping technique. Arch Cardiovasc Dis. 2016;109(12):659-66. DOI: 10.1016/i. acvd.2016.02.012 PMID: 27402154

43. Manning WJ, Weintraub RM, Waksmonski CA, Haering JM, Rooney PS, Maslow AD, et al. Accuracy of transesophageal echocardiography for identifying left atrial thrombi. A prospective, intraoperative study. Ann Intern Med. 1995;123(11):817-22. PMID: 7486462

44. Dentamaro I, Vestito D, Michelotto E, De Santis D, Ostuni V, Caded$\mathrm{du} \mathrm{C}$, et al. Evaluation of left atrial appendage function and thrombi in patients with atrial fibrillation: from transthoracic to real time $3 \mathrm{D}$ transesophageal echocardiography. Int J Cardiovasc Imaging. 2016. DOI: $10.1007 / \mathrm{s} 10554-016-1026-6$ PMID: 27853971

45. Jung PH, Mueller M, Schuhmann C, Eickhoff M, Schneider P, Seemueller G, et al. Contrast enhanced transesophageal echocardiography in patients with atrial fibrillation referred to electrical cardioversion improves atrial thrombus detection and may reduce associated thromboembolic events. Cardiovasc Ultrasound. 2013;11(1):1. DOI: $10.1186 / 1476-7120-11-1$ PMID: 23295101

46. Hong SJ, Kim JY, Kim JB, Sung JH, Wook Kim D, Uhm JS, et al. Multidetector computed tomography may be an adequate screening test to reduce periprocedural stroke in atrial fibrillation ablation: a multicenter propensity-matched analysis. Heart Rhythm. 2014;11(5):76370. DOI: 10.1016/j.hrthm.2014.01.026 PMID: 24469219

47. Patel A, Au E, Donegan K, Kim RJ, Lin FY, Stein KM, et al. Multidetector row computed tomography for identification of left atrial appendage filling defects in patients undergoing pulmonary vein isolation for treatment of atrial fibrillation: comparison with transesophageal echocardiography. Heart Rhythm. 2008;5(2):253-60. DOI: 10.1016/j.hrthm.2007.10.025 PMID: 18242550

48. Wu X, Wang C, Zhang C, Zhang Y, Ding F, Yan J. Computed tomography for detecting left atrial thrombus: a meta-analysis. Arch Med Sci. 2012;8(6):943-51. DOI: 10.5114/aoms.2012.32400 PMID: 23319965

49. Romero J, Husain SA, Kelesidis I, Sanz J, Medina HM, Garcia MJ. Detection of left atrial appendage thrombus by cardiac computed tomography in patients with atrial fibrillation: a meta-analysis. Circ Cardiovasc Imaging. 2013;6(2):185-94. DOI: 10.1161/CIRCIMAGING.112.000153 PMID: 23406625

50. Hur J, Kim YJ, Lee HJ, Nam JE, Ha JW, Heo JH, et al. Dual-enhanced cardiac CT for detection of left atrial appendage thrombus in patients with stroke: a prospective comparison study with transesophageal echocardiography. Stroke. 2011;42(9):2471-7. DOI: 10.1161/ STROKEAHA.110.611293 PMID: 21757676

51. Hur J, Kim YJ, Lee HJ, Nam JE, Hong YJ, Kim HY, et al. Cardioembolic stroke: dual-energy cardiac CT for differentiation of left atrial appendage thrombus and circulatory stasis. Radiology. 2012;263(3):688-95. DOI: 10.1148/radiol.12111691 PMID: 22495682

52. Lempereur M, Aminian A, Freixa X, Gafoor S, Kefer J, Tzikas A, et al. Device-associated thrombus formation after left atrial appendage occlusion: A systematic review of events reported with the Watchman, the Amplatzer Cardiac Plug and the Amulet. Catheter Cardiovasc Interv. 2017. DOI: $10.1002 / \mathrm{ccd} .26903$ PMID: 28145040

53. Main ML, Fan D, Reddy VY, Holmes DR, Gordon NT, Coggins TR, et al. Assessment of Device-Related Thrombus and Associated Clinical Outcomes With the WATCHMAN Left Atrial Appendage Closure Device for Embolic Protection in Patients With Atrial Fibrillation (from the PROTECT-AF Trial). Am J Cardiol. 2016;117(7):1127-34. DOI: 10.1016/j.amjcard.2016.01.039 PMID: 26993976

54. Bajaj NS, Parashar A, Agarwal S, Sodhi N, Poddar KL, Garg A, et al.
Percutaneous left atrial appendage occlusion for stroke prophylaxis in nonvalvular atrial fibrillation: a systematic review and analysis of observational studies. JACC Cardiovasc Interv. 2014;7(3):296-304. DOI: 10.1016/j.jcin.2013.11.010 PMID: 24650403

55. Aminian A, Lalmand J, Tzikas A, Budts W, Benit E, Kefer J. Embolization of left atrial appendage closure devices: A systematic review of cases reported with the watchman device and the amplatzer cardiac plug. Catheter Cardiovasc Interv. 2015;86(1):128-35. DOI: 10.1002/ccd.25891 PMID: 25676316

56. Berti S, Paradossi U, Meucci F, Trianni G, Tzikas A, Rezzaghi M, et al. Periprocedural intracardiac echocardiography for left atrial appendage closure: a dual-center experience. JACC Cardiovasc Interv. 2014;7(9):1036-44. DOI: 10.1016/j.jcin.2014.04.014 PMID: 25234677

57. Masson JB, Kouz R, Riahi M, Nguyen Thanh HK, Potvin J, Naim C, et al. Transcatheter Left Atrial Appendage Closure Using Intracardiac Echocardiographic Guidance From the Left Atrium. Can J Cardiol. 2015;31(12):1497 e7- e14. DOI: 10.1016/j.cjca.2015.04.031 PMID: 26255216

58. Matsuo Y, Neuzil P, Petru J, Chovanec M, Janotka M, Choudry S, et al. Left Atrial Appendage Closure Under Intracardiac Echocardiographic Guidance: Feasibility and Comparison With Transesophageal Echocardiography. J Am Heart Assoc. 2016;5(10). DOI: 10.1161/JAHA.116.003695 PMID: 27680664

59. Frangieh AH, Alibegovic J, Templin C, Gaemperli O, Obeid S, Man$\mathrm{ka} \mathrm{R}$, et al. Intracardiac versus transesophageal echocardiography for left atrial appendage occlusion with watchman. Catheter Cardiovasc Interv. 2016. DOI: 10.1002/ccd.26805 PMID: 27649848

60. Chan NY, Lau CL, Tsui PT, Lo YK, Mok NS. Experience of left atrial appendage closure performed under conscious sedation. Asian Cardiovasc Thorac Ann. 2015;23(4):394-8. DOI: 10.1177/0218492314548231 PMID: 25178469

61. Ternacle J, Lellouche N, Deux JF, Dubois-Rande JL, Teiger E, Lim P. Left atrial appendage closure monitoring without sedation: a pilot study using intracardiac echocardiography through the oesophageal route. EuroIntervention. 2015;11(8):936-41. DOI: 10.4244/EIJY14M07_17 PMID: 26696567

62. MacDonald ST, Newton JD, Ormerod OJ. Intracardiac echocardiography off piste? Closure of the left atrial appendage using ICE and local anesthesia. Catheter Cardiovasc Interv. 2011;77(1):124-7. DOI: 10.1002/ccd.22652 PMID: 20517996

63. Ren JF, Marchlinski FE, Supple GE, Hutchinson MD, Garcia FC, Riley MP, et al. Intracardiac echocardiographic diagnosis of thrombus formation in the left atrial appendage: a complementary role to transesophageal echocardiography. Echocardiography. 2013;30(1):7280. DOI: 10.1111/j.1540-8175.2012.01819.x PMID: 23006427

64. Daoud EG, Kalbfleisch SJ, Hummel JD. Intracardiac echocardiography to guide transseptal left heart catheterization for radiofrequency catheter ablation. J Cardiovasc Electrophysiol. 1999;10(3):358-63. PMID: 10210498

65. Balzer J, Zeus T, Hellhammer K, Veulemans V, Eschenhagen S, Kehmeier E, et al. Initial clinical experience using the EchoNavigator $((\mathrm{R}))$-system during structural heart disease interventions. World J Cardiol. 2015;7(9):562-70. DOI: 10.4330/wjc.v7.i9.562 PMID: 26413233

66. Gao G, Penney G, Ma Y, Gogin N, Cathier P, Arujuna A, et al. Registration of $3 \mathrm{D}$ trans-esophageal echocardiography to X-ray fluoroscopy using image-based probe tracking. Med Image Anal. 2012;16(1):3849. DOI: 10.1016/j.media.2011.05.003 PMID: 21624845

67. Jungen C, Zeus T, Balzer J, Eickholt C, Petersen M, Kehmeier E, et al. Left Atrial Appendage Closure Guided by Integrated Echocardiography and Fluoroscopy Imaging Reduces Radiation Exposure. PLoS One. 2015;10(10):e0140386. DOI: 10.1371/journal.pone.0140386 PMID: 26465747

68. Orlov MV, Hoffmeister P, Chaudhry GM, Almasry I, Gijsbers GH, Swack T, et al. Three-dimensional rotational angiography of the left atrium and esophagus--A virtual computed tomography scan in the electrophysiology lab? Heart Rhythm. 2007;4(1):37-43. DOI: 10.1016/j.hrthm.2006.10.003 PMID: 17198987

69. De Potter T, Jr., Bardhaj G, Viggiano A, Morrice K, Geelen P. Three-dimensional Rotational Angiography as a Periprocedural Imaging Tool in Atrial Fibrillation Ablation. Arrhythm Electrophysiol Rev. 2014;3(3):173-6. DOI: 10.15420/aer.2014.3.3.173 PMID: $\underline{26835087}$ 